\title{
Effect of sonication on the reactivity of silica fume in Portland cement mortars
}

\section{Martínez-Velandia}

Instituto de Ciencia y Tecnología del Hormigón (ICITECH), Universidad Politécnica de Valencia, Camino de Vera S/N, 46022, Valencia, Spain J. Payá

Instituto de Ciencia y Tecnología del Hormigón (ICITECH), Universidad Politécnica de Valencia, Camino de Vera S/N, 46022, Valencia, Spain

\section{J. Monzó}

Instituto de Ciencia y Tecnología del Hormigón (ICITECH), Universidad Politécnica de Valencia, Camino de Vera S/N, 46022, Valencia, Spain M. V. Borrachero

Instituto de Ciencia y Tecnología del Hormigón (ICITECH), Universidad Politécnica de Valencia, Camino de Vera S/N, 46022, Valencia, Spain

Currently, the use of silica fume for the production of mortars and high-performance concrete is of great importance to the construction materials sector. Different applications of silica fume have generated extensive studies about its high reactivity as a pozzolanic material, in addition to its effect on the properties of some materials within which it is incorporated. In this study a sonication process was applied by means of which the deagglomeration of the larger particles of densified silica fume (CSF) was achieved. The result is a CSF treated with the ultrasound probe, which is obtained for different tests where the parameters of sonication such as sonication power level and sonication time are varied. This treatment makes it possible to increase the quantity of submicrometric particles in the sample. The effect of sonication process on CSF produces a greater quantity of very fine particles, which improve the pozzolanic reactivity of silica fume and increase the fixation of hydrated lime. This behaviour also produces higher mechanical strength in mortars manufactured with sonicated silica fume (SSF). The mechanical strengths of SSF mortars were greater than those for control and CSF mortar. Different percentages of cement were substituted (between 0 and $15 \%$ by weight), and in all cases the SSF mortars showed important differences from the CSF mortar. It was observed that for the longest sonication times and highest sonication power levels, mechanical strengths were increased.

\section{Introduction}

Owing to some technological advances which have occurred in recent years, the construction sector has benefited from diverse and new materials that differ from traditional ones. These materials offer the possibility of improving the behaviour of concrete in different service conditions. The use of these materials has increased in the last few years because they can offer greater performance in all types of projects (Hooton, 1993; Malhotra and Metha, 1996; Roberts, 1989). Nowadays, the pozzolanic material known as densified silica fume (CSF) is one of the most commonly used in construction due to the improvement of mechanical strength, durability, resistance to environmental attacks and other benefits it offers (Bushlaibi, 2004; Hooton, 1993; Mehmet and Erhan, 2007). The pozzolanic activity of CSF has been measured based on the fixed hydrated lime due to the formation of new calcium silicate hydrates $(\mathrm{C}-\mathrm{S}-\mathrm{H})$ products, showing that CSF presented a decrease in reactivity when it was in a densified state if compared with its original nondensified state (Sanchez de Rojas et al., 1999).

Previous studies have shown that CSF could perform as a filler, filling out the spaces between cement particles and aggregates (Sidney and Sadananda, 2006). The specific surface area of CSF in a densified state was calculated by two methods, the nitrogen adsorption method (BET) and that calculated from the laser diffraction granulometry (LDG) distribution data. Figure 1 shows a CSF agglomerate analysed by each method. It shows that the BET method is not sensitive to the densification state of the CSF; therefore the results obtained with LDG are completely different from those obtained with BET. It suggests that when CSF is densified to be transported, its granulometric distribution is noticeably modified and its pozzolanic activity can be reduced.

To activate the CSF, it has been treated by means of a sonication process in order to modify its densification state and to obtain a finer sample and better granulometric distribution (MartinezVelandia et al., 2008). The material obtained from this process is called sonicated silica fume (SSF) and it has a granulometric distribution that is totally different from CSF. For SSF samples, the volume of particles with a diameter lower than $1 \mu \mathrm{m}$ (submicrometric particles, \% $\mathrm{SP}$ ) was more than $50 \%$ and its mean particle diameter $\left(M_{\mathrm{d}}\right)$ was about $5 \mu \mathrm{m}$. It has been observed that SSF is a material which improves its performance when it is used as a replacement mineral addition substituted in cement mortars that contributes to increase the mechanical strengths and fixations of portlandite (Martinez-Velandia, 2006). When SF particles are included in cement mortars, the cement hydration speed in the first curing days is increased. This effect 


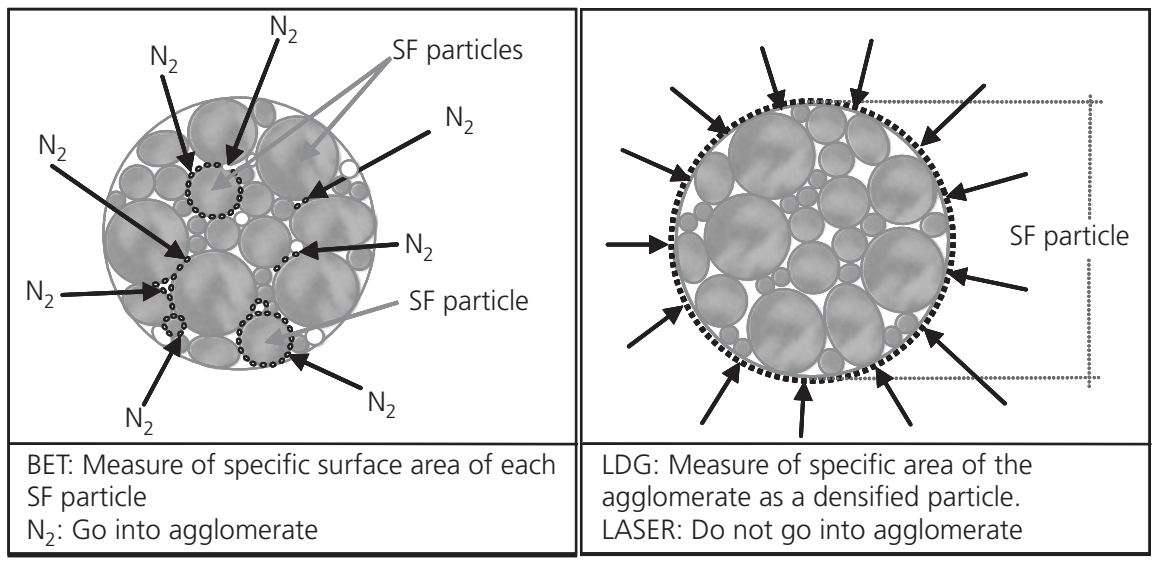

Figure 1. Comparative analysis of specific surface area of a CSF agglomerate

produces a higher quantity of hydrates, increasing the quantity of portlandite available, which later increases the pozzolanic reaction (Appa Rao, 2003). This behaviour has contributed to the success of CSF in a great number of applications in the building materials sector.

For the purposes of this research, the incorporation and effect of two types of silica fume: CSF and SSF on properties of Portland cement mortars have been studied. The effect of CSF and SSF on the properties of mortars in a hardened state has been analysed. To check the activity for each pozzolanic material (CSF and SSF), thermogravimetric analysis studies and mechanical properties studies have been carried out.

\section{Experimental work}

\section{Materials}

Ordinary Portland cement (CEM I-52.5R) was used for preparing the OPC-SF mixtures. Cement A from the first batch was used for preparing $10 \%$ replacement mortars, and cement B from the second batch for 5 and $15 \%$ replacement. The CSF was supplied by Ferroatlántica (Sabón, Spain) and was in a densified state. The SSF was obtained by treatment of CSF with an ultrasound probe. This treatment (Martinez-Velandia et al., 2008) deagglomerates the CSF, increasing the fineness of the SF sample. For the preparation of mortars, a commercial superplasticiser Melment240 obtained from Bettor S.L was used. It was added in different proportions in order to achieve the same workability for the differently prepared mortars. Table 1 shows the chemical composition for the solid materials used.

\section{Sonication of the CSF}

To activate CSF, a physical treatment was applied by means of an ultrasound probe, using different probe power levels and sonication times. The sample was prepared in $600 \mathrm{ml}$ precipitate beakers ( $8 \mathrm{~cm}$ high, $15 \mathrm{~cm}$ in diameter) and suspended in water $(228.4 \mathrm{ml})$, using different silica fume $(\mathrm{SF}) /$ water ratios. The temperature of the slurry was maintained at $20-35^{\circ} \mathrm{C}$ using an external cold water bath. The ultrasound equipment used for the sonication process was the Sonicator S-3000, produced by Misonix. It has a maximum power of $600 \mathrm{~W}$ and a frequency output of $20 \mathrm{kHz}$. Different power levels were used in the experiments. Table 2 shows the sonication power ( $S$, in watts) related to the power level (PL) and data of power per unit mass of SF $\left(P_{\mathrm{g}}, \mathrm{W} / \mathrm{g}\right)$ when different power levels were used. Additionally, the data for supplied energy per unit mass of SF $\left(E_{\mathrm{g}}, \mathrm{J} / \mathrm{g}\right)$ are given in Table 3, when different sonication times have been used. Granulometric curves for CSF and SF sonicated for $25 \mathrm{~min}$ at PL8 $(S=141 \mathrm{~W}, P=2 \cdot 26 \mathrm{~W} / \mathrm{g})$ are shown in Figure 2.

\begin{tabular}{lcrrrrrrrrrrr}
\hline Material & Batch & $\mathrm{SiO}_{2}$ & $\mathrm{Al}_{2} \mathrm{O}_{3}$ & $\mathrm{Fe}_{2} \mathrm{O}_{3}$ & $\mathrm{CaO}$ & $\mathrm{MgO}$ & $\mathrm{SO}_{3}$ & $\mathrm{~K}_{2} \mathrm{O}$ & $\mathrm{Na}_{2} \mathrm{O}$ & $\mathrm{LOI}^{*}$ & $\mathrm{IR}^{\dagger}$ \\
\hline CEM I-52.5R & $\mathrm{A}$ & 19.90 & 5.38 & 3.62 & 63.69 & 2.14 & 3.66 & 1.17 & 0.10 & 2.02 & 0.95 \\
CEM I-52.5R & $\mathrm{B}$ & 22.05 & 5.44 & 3.69 & 62.53 & 2.43 & 3.75 & 1.92 & 0.05 & 1.70 & 0.94 \\
CSF & - & 90.77 & 0.46 & 4.53 & 0.78 & 0.23 & 0.02 & 0.37 & 0.21 & 3.43 & - \\
\hline
\end{tabular}

* LOI, loss on ignition.

$\dagger \mathrm{R}$, insoluble residue. 
Effect of sonication on the reactivity of silica fume in Portland cement mortars Martínez-Velandia, Payá, Monzó and Borrachero

\begin{tabular}{lrc}
\hline$P L$ & $S: W$ & $P_{\mathrm{g}}: W / g$ \\
\hline 3 & 60 & $0 \cdot 96$ \\
4 & 81 & $1 \cdot 30$ \\
6 & 111 & $1 \cdot 78$ \\
8 & 141 & $2 \cdot 26$
\end{tabular}

Table 2. Data of sonication power (S), power level (PL) and power per unit mass $\left(P_{\mathrm{g}}\right)$ of SF

\begin{tabular}{lcccc}
\hline PL & S:W & $P_{\mathrm{g}}: \mathrm{W} / \mathrm{g}$ & US* $: \min$ & $E_{\mathrm{g}}: \mathrm{J} / \mathrm{g}$ \\
\hline 8 & 141 & $2 \cdot 26$ & 5 & 678 \\
& $2 \cdot 26$ & 10 & 1356 \\
& $2 \cdot 26$ & 15 & 2034 \\
& $2 \cdot 26$ & 20 & 2712 \\
& $2 \cdot 26$ & 25 & 3390 \\
\hline
\end{tabular}

* Time of sonication.

Table 3. Data of supplied energy per unit mass of SF

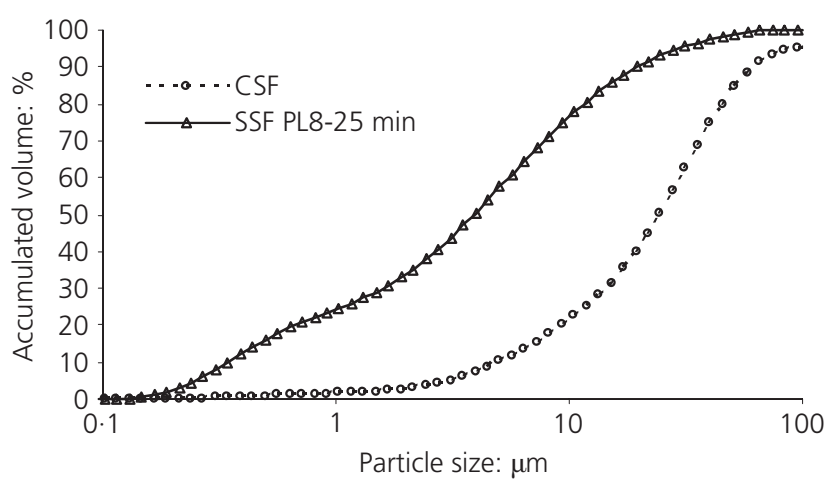

Figure 2. Granulometric curves for CSF and SSF

\section{Thermogravimetric analysis studies}

To determine the fixation of hydrated lime due to pozzolanic reaction, samples of each mortar were taken for selected curing times. The sample was ground in the presence of acetone in order to stop the hydration processes and dried for $30 \mathrm{~min}$ at $60^{\circ} \mathrm{C}$. It was then kept in a dessicator, where it reached room temperature and was finally stored in an Eppendorf vessel. Thermogravimetric analyses (TGA) were carried out using a TGA Mettler-Toledo 850 thermobalance. Aluminium crucibles of $100 \mu$ capacity were used, sealed with a pinholed lid, in order to produce a water vapour-autogenerated atmosphere during the analysis. The sample in the furnace was heated within a range of $35-600^{\circ} \mathrm{C}$, at a heating rate of $10^{\circ} \mathrm{C} / \mathrm{min}$, under a $75 \mathrm{ml} / \mathrm{min}$ gas flow of dry nitrogen. One sample from the mortar specimen with a mechan- ical strength that was close to the average $R_{\mathrm{c}}$ value was taken to be analysed by TGA.

\section{Preparation and tests of cement mortar mixtures}

To analyse the compressive mechanical strength $\left(R_{\mathrm{c}}\right)$ of mortars, they were fabricated using equipment and following procedures according to the UNE-EN 196-1:1996 standard. For each study 12 prismatic mortar specimens were analysed; the average strength $\left(R_{\mathrm{c}}\right)$ was the average of the results for these 12 specimens. Additionally, $10 \%$ of deviation from $R_{\mathrm{c}}$ was taken into account, and those values falling below this were rejected and the $R_{\mathrm{c}}$ was recalculated for the remaining results. The water/cementitious material ratio $(\mathrm{w} / \mathrm{cm})$ was $0 \cdot 35$, and the cementitious material/aggregate ratio $(\mathrm{cm} / \mathrm{a})$ was $1 / 1 \cdot 75$. Cementitious material was the sum of OPC and silica fume. Mortar specimens $(40 \mathrm{~mm} \times 40 \mathrm{~mm} \times 160 \mathrm{~mm})$ were demoulded after $24 \mathrm{~h}$, submerged in lime-saturated water until mechanical testing (20 $\pm 1{ }^{\circ} \mathrm{C}$ and $100 \%$ relative humidity).

\section{Scanning electron microscopy studies}

In order to take the micrographs of the silica fume samples, the scanning electronic microscope (SEM) model JEOL JSM 6300 was used with a voltage of $20 \mathrm{kV}$. The work distance was: $15 \mathrm{~mm}$ and the samples were recovered with gold.

\section{Results and discussion}

\section{Scanning electron microscopy study}

Large particles (macroagglomerates) were identified in the CSF sample (Figure 3(a)) and it can be observed that some macroagglomerates had sizes bigger than $100 \mu \mathrm{m}$, as a result of the densifying process. Somewhat similar results were obtained by Sidney and co-workers (Sidney and Sadananda, 2006; Sidney et al., 2004). These macroagglomerates also confirmed some results obtained in previous studies (Martinez-Velandia, 2006) for silica fume, in which the granulometric distribution of a CSF sample showed more than $50 \%$ of particles with a diameter greater than $180 \mu \mathrm{m}$. The micrograph obtained for the sample SSF-US-20 sonicated at PL3 for $20 \mathrm{~min}$, also shows particles of great size, due to the fact that this sonication power level was not sufficiently effective to deagglomerate the original particles of CSF (Figure 3(b)).

In contrast, for the sample SSF-US-10 sonicated at PL8 for 10 min, the deagglomeration of the CSF particles can be seen. Large particles were not observed and most particles showed diameters less than $2 \mu \mathrm{m}$, as a direct consequence of the effectiveness of the sonication process at this power level (Figure $3(\mathrm{c})$ ). Some microagglomerates can be seen in this image, suggesting that the deagglomeration process had not been completed in these conditions. It has also been reported (Martinez-Velandia et al., 2008) that SSF has a granulometric distribution that is finer than densified CSF, which confirms the differences observed by SEM. 
Effect of sonication on the reactivity of silica fume in Portland cement mortars

Martínez-Velandia, Payá, Monzó and

Borrachero

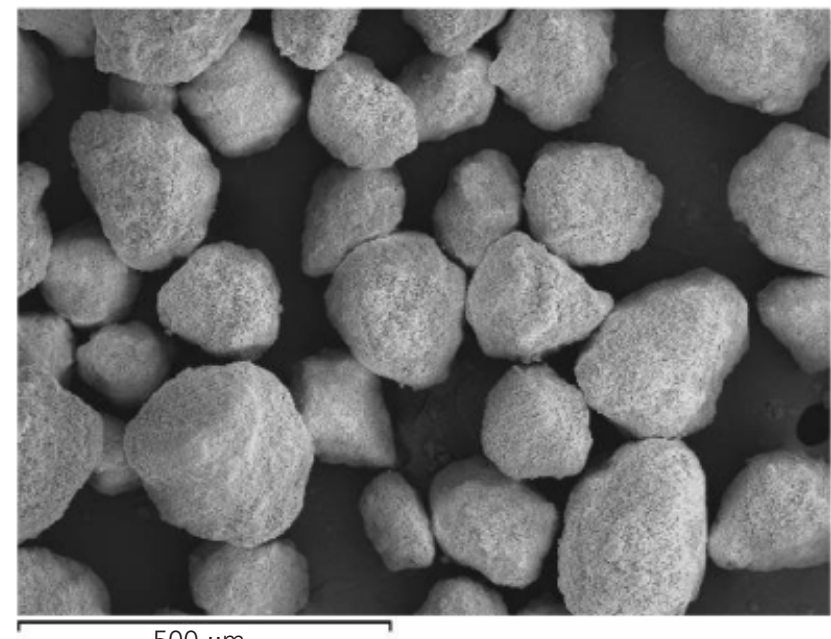

$500 \mu \mathrm{m}$

(a)

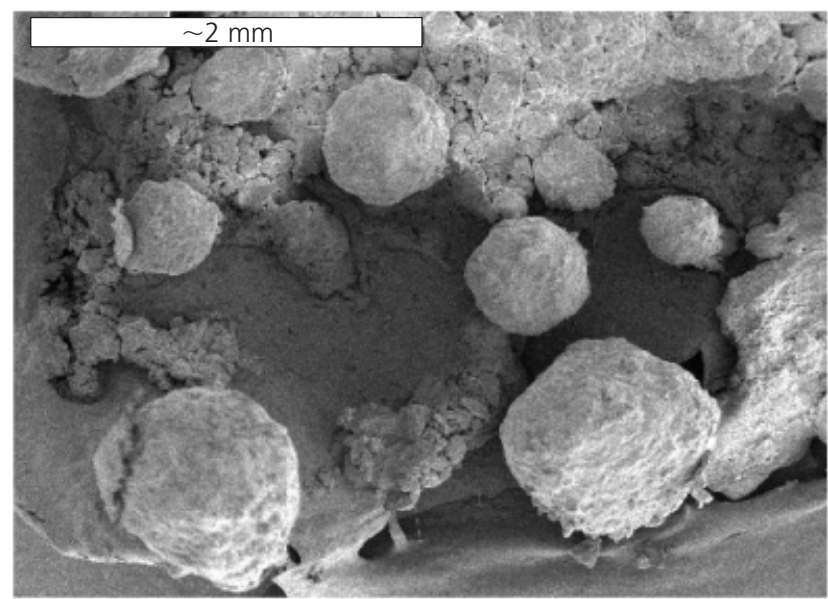

(b)

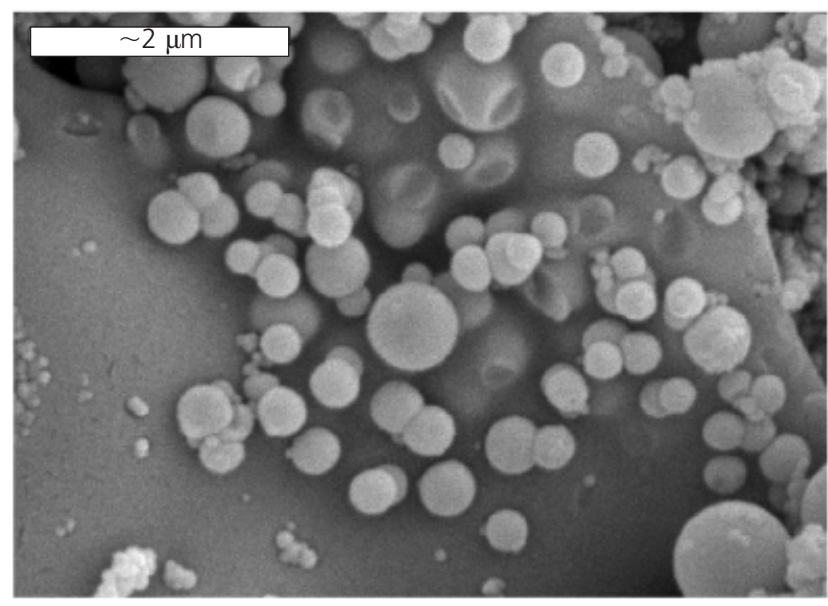

(c)

Figure 3. SEM images for different samples of SF: (a) non-treated CSF; (b) SSF-US-20 at PL3; (c) SSF-US-10 at PL8
Other authors (Baweja et al., 2003; Shayan et al., 1993) have reported similar SF macro-agglomerates in pastes, mortars and concretes made with densified silica fume (CSF) and particles larger than $100 \mu \mathrm{m}$ were found.

These results confirm the substantial differences between the sonication power levels and their effect on the CSF agglomerates. It is obvious that the effectiveness of the probe is greater at the highest power levels, as reported previously (Martinez-Velandia et al., 2008).

\section{Studies on mechanical strength}

Study in mortars substituted with 5, 10 and $15 \%$ of SF: variation of the sonication time with constant power level

Prismatic mortar specimens replacing 5, 10 and $15 \%$ of cement by SF (in original state CSF and after sonication SSF) were prepared at w/cm ratio 0.35 and cured for 7 and 28 days. Cement A from the first batch was used for preparing 10\% replacement mortars, and cement $\mathrm{B}$ from the second batch for 5 and $15 \%$ replacement. The sonication process was performed at PL8 $\left(S=141 \mathrm{~W}, P_{\mathrm{g}}=2.26 \mathrm{~W} / \mathrm{g}\right.$ ); the ultrasound probe becomes very effective at this level and the large CSF particles can be deagglomerated easily. Similarly, different sonication times between 5 and $25 \mathrm{~min}$ (see Table 3) were studied. Table 4 shows the dosages for prepared mortars and Table 5 summarises the compressive mechanical strengths of the prepared mortars for 7- and 28-day curing ages.

For each case, control mortars (without SF) were prepared, in order to compare the effect of the pozzolanic material. The values for control mortars in the $10 \%$ SF series were slightly different from those obtained for control mortars in the 5 and $15 \%$ series. Therefore, it was decided to analyse the results by calculating the strength activity index (SAI), defined as the ratio between the strength of SF-mortar and the control mortar at the same curing age.

It can be seen that for mortars substituted with $10 \% \mathrm{SF}$, first the CSF mortar $(62.3 \mathrm{MPa})$ could not equal the strength of the control mortar at 7 days $(63.0 \mathrm{MPa})$, whereas the SSF mortars exceeded the values of the control mortar. Second, for 28 days of curing, all the mortars with SF exceeded the control mortar, with the highest strength values being for the SSF US-25 mortar. Again, SSF yielded higher strength value than the original CSF. In all cases, a general trend was observed: the 7- and 28-day strength increased with the sonication time of the suspension.

In respect of mortars substituted with $5 \% \mathrm{SF}$, the CSF mortar mechanical strengths at 7 days of curing did not exceed the value of the control mortar as found for the $10 \%$ replacement level. However, the values for SSF mortars exceeded the control mortar, and they continued to increase as the sonication time increased. For 28 days of curing, SSF mortars continued to exceed the strength of both control and CSF mortars. 


\begin{tabular}{lccccc}
\hline Mortar type & Cement: $g$ & Water: & SF: & Aggregate: $g$ & Additive: \% \\
\hline Control & 652.5 & 228.4 & - & 1147.5 & 0.5 \\
Replacement 5\% SF & 619.9 & 228.4 & 32.6 & 1147.5 & 1.5 \\
Replacement 10\% SF & 587.3 & 228.4 & 65.3 & 1147.5 & 1.5 \\
Replacement 15\% SF & 554.6 & 228.4 & 97.9 & 1147.5 & 1.5
\end{tabular}

Table 4. Dosages for control and SF (CSF or SSF) substituted

mortars with 5, 10 and $15 \%$ replacing levels

Mortar type

$R_{\mathrm{c}}$, compressive mechanical strengths: MPa (standard deviation values in brackets)

\begin{tabular}{|c|c|c|c|c|c|c|}
\hline & \multicolumn{2}{|c|}{$5 \% \mathrm{SF}$} & \multicolumn{2}{|c|}{$10 \% \mathrm{SF}$} & \multicolumn{2}{|c|}{$15 \%$ SF } \\
\hline & 7 days & 28 days & 7 days & 28 days & 7 days & 28 days \\
\hline Control & $70 \cdot 1(1 \cdot 16)$ & $80.6(1.55)$ & $63.0(1.67)$ & $76 \cdot 6(2 \cdot 38)$ & $70 \cdot 1(1 \cdot 16)$ & $80.6(1.55)$ \\
\hline With CSF & $66.9(2.52)$ & $83.2(1.06)$ & $62.3(0.66)$ & $82 \cdot 1(1.56)$ & $69 \cdot 3(1 \cdot 24)$ & $86.4(1.61)$ \\
\hline With SSF US-5 & $70.2(0.85)$ & $88.1(1.11)$ & $66 \cdot 1(1.51)$ & $83.4(1.75)$ & $72.9(1.60)$ & $86.4(1.24)$ \\
\hline With SSF US-10 & $72.8(0.90)$ & $90.0(1.73)$ & $68.0(1.58)$ & $86.0(2.89)$ & $76 \cdot 1(1 \cdot 19)$ & $93.0(2.82)$ \\
\hline With SSF US-15 & $74.8(1.92)$ & $91.8(1.43)$ & $69.7(1.57)$ & $89.9(2.73)$ & $76.8(1.07)$ & $94.3(2.83)$ \\
\hline With SSF US-20 & $74.8(1 \cdot 38)$ & $93.0(1.42)$ & $69.9(0.93)$ & $89.3(2 \cdot 84)$ & $78.8(2.44)$ & $96.6(1.92)$ \\
\hline With SSF US-25 & $75 \cdot 3(1.21)$ & $91.0(2.31)$ & $71.5(1.63)$ & $90.0(2.06)$ & $78.2(1.72)$ & 95.9 (1.98) \\
\hline
\end{tabular}

Table 5. Compressive mechanical strengths for control and SF mortars substituted with 5, 10 and 15\% of CSF and SSF (PL8): different sonication times

With respect to mortars substituted with $15 \%$ SF (from the same batch of cement as the $5 \%$ replacement), an increase of $R_{\mathrm{c}}$ values was observed when compared with the corresponding $5 \%$ replacement. This behaviour can be attributed to the higher development of pozzolanic reaction when the amount of SF was increased. There was also an increase in the compressive strength when the sonication time was increased. The differences in absolute terms between the compressive strengths among the mortars containing CSF and SSF US-25 for 7 and 28 days of curing were approximately $9 \mathrm{MPa}$ for both curing ages, showing the significant influence of the sonication process on the pozzolanic properties of SF for mortars with the highest replacement level.

Conversely, in mortars substituted with as much as or more than $10 \%$ (for sonication times under $10 \mathrm{~min}$ ) for 28 days of curing, CSF had already reacted to an important degree since their compressive strength values were greater than for control mortars. For this curing age, CFS mortars showed similar compressive strength to those found for SSF mortars with sonication times under $10 \mathrm{~min}$, suggesting that the effect of the pozzolanic contribution was important for both pozzolanic materials. However, these strength values were not equal to those for mortars prepared with SSF sonicated for more than $10 \mathrm{~min}$. This behav- iour demonstrates that the sonication process enhanced the pozzolanic properties of silica fume for both early and long curing ages.

Furthermore, it can be observed that the 7- and 28-day strength values obtained for 5\% replacement levels using SSF US-25 were higher than those using $15 \%$ replacement of CSF. These data show that it was possible to enhance mechanical properties when SSF was used instead of CSF, dosifying lower quantities of sonicated pozzolan.

In Figure 4, the values of the SAI are given for each of the SF mortars studied. SAI is the ratio between the compressive strength of the mortar with $\mathrm{SF}\left(R_{\mathrm{c}_{\mathrm{i}}}\right)$ and the compressive strength of the control mortar $\left(R_{\mathrm{c}_{0}}\right)$ at the same curing age.

It can be observed that, in general, the SSF mortars showed an increase in their relative mechanical strength for 7 and 28 days of curing. The beneficial effect of the sonication process on the CSF is continuous and more effective when the sonication times are longer. Certainly, slight differences could be found for sonication times over $10 \mathrm{~min}$. For 7 days' curing time, the SAI values for SSF mortars exceeded the CSF mortar, and were equal or greater than this unit. The same was observed for 28-day cured SSF 


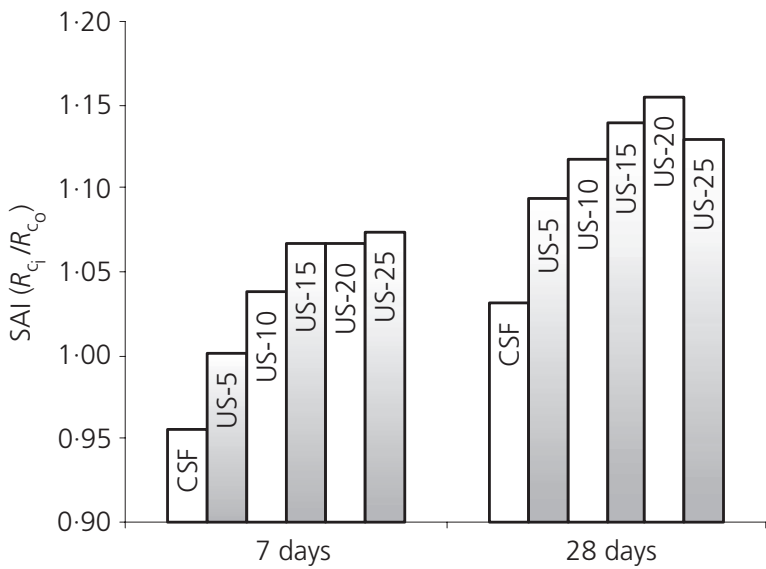

(a)

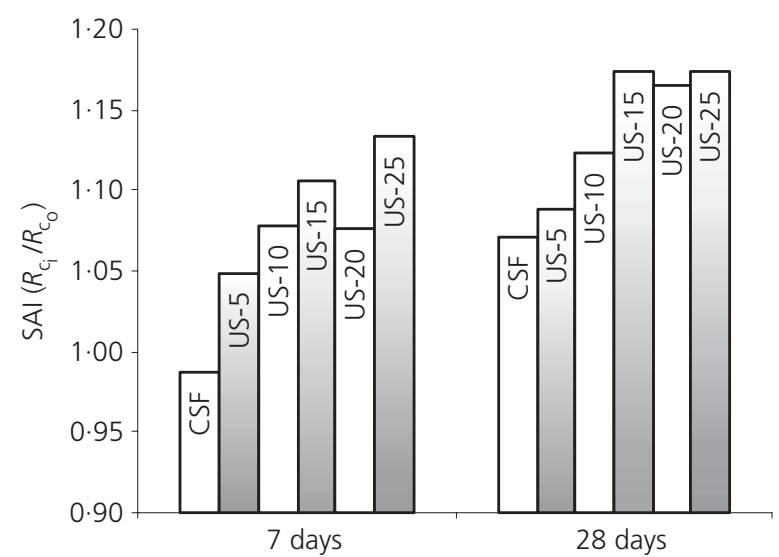

(b)

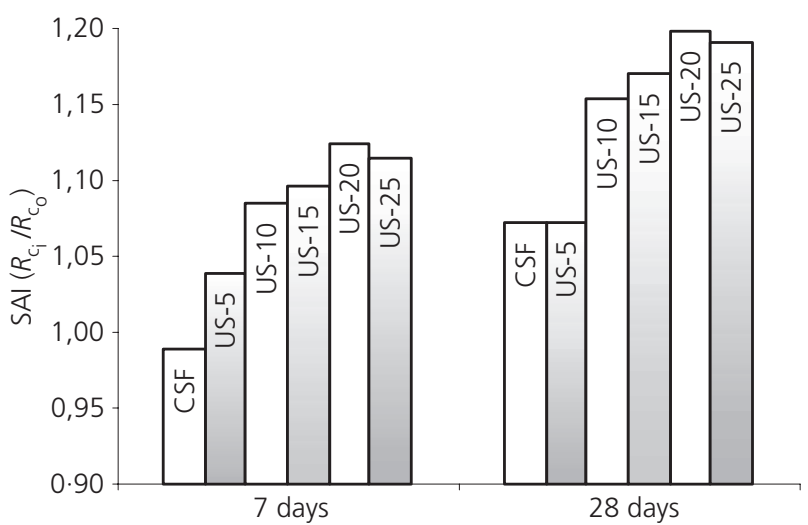

(c)

Figure 4. SAI values for cement-SF mortars substituted with (a) $5 \%$, (b) $10 \%$ and (c) $15 \%$ SF at different sonication times

mortars. Furthermore, the greatest activity was observed in the mortars with $5 \% \mathrm{SSF}$ treated for as much as or more than $10 \mathrm{~min}$ of sonication, which in just 7 days of curing exceeded those SAI values obtained by the mortar with $5 \%$ CSF over 28 days of curing. Furthermore, for 28 days of curing for 5\% replacement mortars, it was observed that the SSF (US-20) mortar presented the highest SAI value, eventually surpassing those values obtained by control mortars by $15 \%$.

It is possible to analyse these results by calculating an index that could supply some additional information about the effect of the sonication time on mortars' strength. The proposed index is called 'mechanical effectiveness by sonication' (MES) and is calculated as the ratio between $R_{\mathrm{c}}$ for SSF mortar and $R_{\mathrm{c}}$ for CSF mortar at the same age and replaced percentage.

It was observed (see Figure 5) that for higher sonication times the MES values increased for 5, 10 and $15 \%$ SF replacements. Two adjustment curves for 7 and 28 curing days were depicted and their equations calculated. Higher MES values were obtained for 7 days, suggesting that the relative effectiveness of sonication for this curing age was more important.

\section{Variation of the sonication power level at constant sonication time: effect on the mechanical properties of SF mortars}

The mechanical strengths of different mortars substituted with $10 \% \mathrm{SF}$ were evaluated at a $\mathrm{w} / \mathrm{cm}$ ratio of $0 \cdot 35$, using the cement $\mathrm{B}$ from the second batch (as used in the previous section for 5 and $15 \%$ replacement mortars). The sonication power level (see Table 2) was varied between PL3 $\left(S=60 \mathrm{~W}, P_{\mathrm{g}}=0.96 \mathrm{~W} / \mathrm{g}\right)$ and PL8 $\left(S=141 \mathrm{~W} ; P_{\mathrm{g}}=2.26 \mathrm{~W} / \mathrm{g}\right)$, and the sonication time remained constant at $20 \mathrm{~min}$. Table 6 shows the values of mechanical strengths for cement mortars substituted with $10 \%$ SF after 7 and 28 days of curing.

CSF mortar over 7 days of curing did not exceed the value obtained by the control mortar, this behaviour was also observed for mortars substituted with SSF at the lowest power levels PL3 and PL4. However, SSF mortars at PL6 and PL8 indicated substantial mechanical increases, exceeding the control mortar strength and the SSF mortar strengths at lower sonication power levels. For 28 days of curing, all the mortars showed important

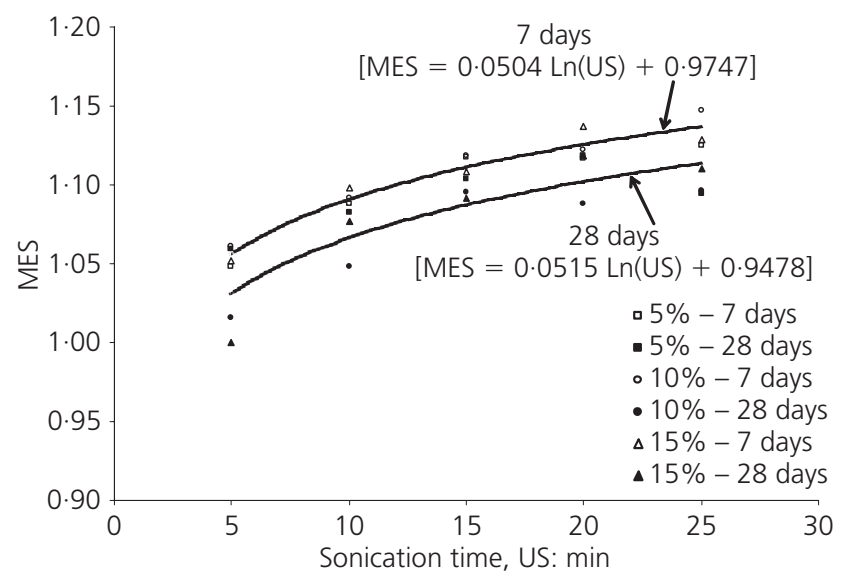

Figure 5. MES values for cement-SF mortars substituted with 5, 10 and $15 \%$ SF at different sonication times 
w/cm Mortar type $\quad R_{c}$, compressive mechanical strengths: MPa (standard deviation values in brackets)

\begin{tabular}{cccc}
\cline { 3 - 3 } & & & \\
& & & \\
& & & \\
& & days & days \\
\hline 35 & Control & $70.1(1.16)$ & $80.6(1.55)$ \\
& CSF & $65.4(1.76)$ & $84.0(1.16)$ \\
PL 3 - SSF & $67.4(1.15)$ & $84.7(2.37)$ \\
PL 4 - SSF & $69.9(1.20)$ & $84.7(1.39)$ \\
PL 6 - SSF & $74.7(1.01)$ & $88.6(1.47)$ \\
PL 8 - SSF & $74.9(0.72)$ & $91.2(1.48)$
\end{tabular}

Table 6. Compressive mechanical strengths for cement mortars substituted with $10 \% \mathrm{SF}$ : effect of the sonication power level

increases, with just SSF-PL8 mortar obtaining the highest mechanical strength.

The calculated SAI values are shown in Figure 6. It can be seen that SAI was greater for samples prepared with SF sonicated at PL6 and PL8, at 7 and 28 days of curing. It is evident that the PL8 treatment generated the deagglomeration of a large quantity of CSF particles, which elevated their reactivity and therefore the mortars prepared with SSF at PL8 presented the highest SAI, reaching values of 1.07 and 1.13 at 7 and 28 days, respectively.

These differences observed between, on the one hand, mortars substituted with SSF sonicated at PL3 and PL4 and, on the other hand, mortars substituted with SSF sonicated at PL6 and PL8 can be related directly to the results observed in previous studies (Martinez-Velandia et al., 2008) in which it can be seen that SSF at higher power levels produced a very high submicrometric particle percentage $(\% \mathrm{SP})$ and, consequently their SAI values were also high. On the other hand, SSF mortars prepared using

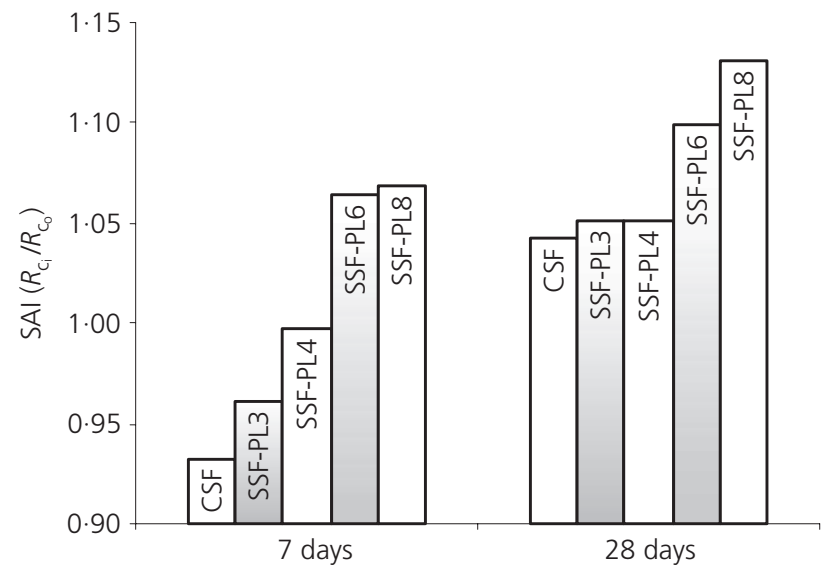

Figure 6. Value of the SAI for cement mortars substituted with $10 \%$ SSF: variation of sonication power level low-energy sonication (PL3 and PL4) showed very low SP\% and produced the lowest SAI values. This behaviour shows that the development of high levels of mechanical strength depended most significantly on the quantity of submicrometric particles (smaller than $1 \mu \mathrm{m}$ in diameter). Furthermore, the better mechanical performance of SSF-PL6 and SSF-PL8 mortars did not correspond to the threshold sonication power level observed from granulometric data (Martinez-Velandia et al., 2008). Thus the granulometric data demonstrated that there was a threshold sonication power level under which the SP\% was very low and, in this case, effective enhancement of mechanical properties did not occur. In contrast, a clear beneficial effect on mechanical behaviour was measured over this threshold,

Table 7 shows the values obtained for mechanical effectiveness by way of the sonication index. In this case, MES values for 7 curing days increased from 1.08 for $S=60 \mathrm{~W}$ to 1.20 for $S=141 \mathrm{~W}$. A similar behaviour was observed for 28 curing days, the MES values were at a lower level over 7 days in accordance with data depicted in Figure 5.

\section{Thermogravimetric studies}

Study on mortars substituted with $10 \%$ SF: variation of the sonication times at constant power level

This study was conducted on mortars prepared with SSF at PL8 (cement A), applying sonication times between 5 and $25 \mathrm{~min}$, for a w/cm ratio of 0.35 and 28 days of curing. Table 8 summarises the thermogravimetric data calculated from the thermogravimetric curves. Portlandite fixed by pozzolan was calculated by comparing the portlandite content of the control mortar (Payá et al., 2004). It can be observed that there was a remarkable increase in the fixation of portlandite between SSF-US 5 and CSF mortars. The effectiveness of sonication was obvious from the pozzolanic reaction increasing the percentages of hydrated lime fixation from $29 \cdot 4$ to $48 \cdot 1 \%$. This means that with only $5 \mathrm{~min}$ of sonication, portlandite fixation was increased by almost $20 \%$ in SSF mortar. As the sonication time increased, portlandite fixation also increased, from $48 \cdot 1 \%$ for SSF-US5 to $57 \cdot 3 \%$ for SSF-US25. This increase in portlandite fixation could be related to SF fineness (Martinez-Velandia et al., 2008), in accordance with the compressive strength gain previously described.

The weight loss related to hydrates, with the exception of portlandite, was calculated by the difference of total weight loss

\begin{tabular}{lcccc}
\hline Curing days & \multicolumn{5}{c}{ Sonication power: W } \\
\cline { 2 - 5 } & 60 & 81 & 111 & 141 \\
\hline 7 days & 1.08 & 1.12 & 1.20 & 1.20 \\
28 days & 1.03 & 1.03 & 1.08 & 1.11
\end{tabular}

Table 7. MES values for cement-SF mortars substituted with $10 \%$ SF: variation of sonication power 


\begin{tabular}{|c|c|c|c|}
\hline Mortars & Total weight loss: $\%\left(35-600^{\circ} \mathrm{C}\right)$ & Weight loss for hydrates: \% & Fixed portlandite: \% \\
\hline
\end{tabular}

\begin{tabular}{lrrr}
\hline CSF & 10.64 & 9.66 & 29.4 \\
SSF - US 5 & 11.81 & 11.09 & $48 \cdot 1$ \\
SSF - US 10 & 12.55 & 11.86 & $50 \cdot 4$ \\
SSF - US 15 & 12.77 & $12 \cdot 10$ & 51.2 \\
SSF - US 20 & 11.54 & 10.92 & 55.6 \\
SSF - US 25 & 11.32 & 10.73 & 57.3
\end{tabular}

Table 8. TGA data for 28-days curing mortars substituted with $10 \%$ SF: effect of the sonication time at PL8

over the range $35-600^{\circ} \mathrm{C}$ minus the water released by the decomposition of $\mathrm{Ca}(\mathrm{OH})_{2}$ at about $550^{\circ} \mathrm{C}$ (see Figure 7). The hydrates evaluated by this method were typical of the reaction of Portland cement in water $(\mathrm{C}-\mathrm{S}-\mathrm{H}$, calcium aluminate hydrates, ettringite, etc.) plus the $\mathrm{C}-\mathrm{S}-\mathrm{H}$ from the pozzolanic reaction between amorphous silica (Martinez-Velandia, 2006) in SF and calcium hydroxide released by Portland cement during its hydration. Weight loss for hydrates in SSF systems were higher than those found for mortar containing untreated SF, suggesting that the pozzolanic reaction was extended. However, the increase in weight loss for hydrates was observed when the sonication time increased from $5(11.09 \%)$ to $15 \mathrm{~min}(12 \cdot 10 \%)$, whereas for 20 and $25 \mathrm{~min}$ of sonication, this value was slightly lower. This behaviour suggests that the inclusion of a more dispersed pozzolanic addition modified the water content of hydrates in these mixtures.

Study on mortars substituted with $10 \%$ SF: variation of sonication power level at constant sonication time

Mortars prepared with $10 \% \mathrm{SSF}$ (sonication time of $20 \mathrm{~min}$ ) and cement $\mathrm{B}$ were studied, at a w/ $\mathrm{cm}$ ratio of $0 \cdot 35$, for 7 and 28 days of curing. SSF was sonicated at different power levels: PL3, PL4,

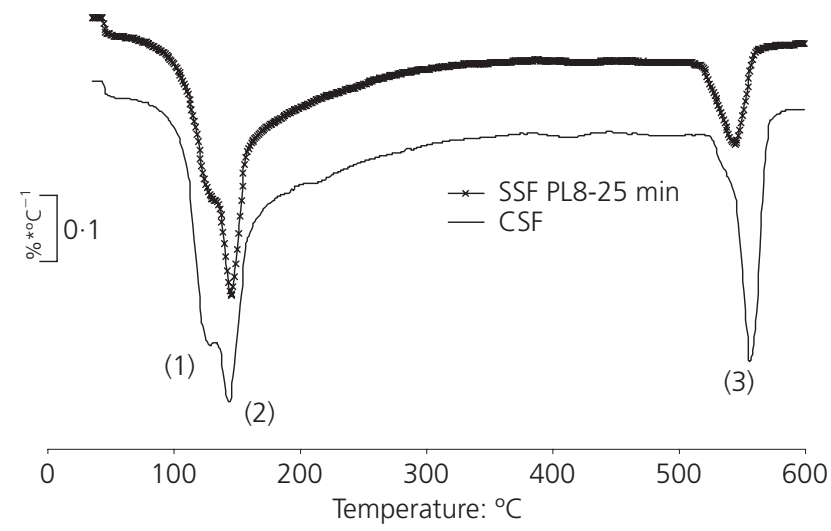

Figure 7. Dynamic thermogravimetric analysis curves for CSF and SSF-US25 replaced mortars
PL6 and PL8 (Table 2 summarises the sonication power and the power by unit mass).

There was an increase in the hydrated lime fixation at higher sonication power levels (Table 9). In respect of the SSF mortar at PL8, the highest fixations of portlandite were measured for 7- and 28-day curing times. This confirms the effect of the sonication on pozzolanic reaction when the macroagglomerates are destroyed through the sonication process. Furthermore, the smallest fixations of hydrated lime were observed for the PL3-SSF mortar, which were the same at 7 as for 28 days. In previous studies (Martinez-Velandia et al., 2008), it was observed that an increase in the sonication times of CSF increased the quantity of submicrometric particles. This effect was transformed by increasing percentages of hydrated lime fixation, where the values vary from 34.5 and $39.8 \%$ for PL3-SSF, to 64.8 and $77.9 \%$ for PL8SSF at 7 and 28 days, respectively. This behaviour was in accordance with the compressive strengths of mortars reported.

\section{Conclusions}

(a) With regard to the SEM images, a superior deagglomeration of the particles was observed for the SSF sample. Moreover, the largest quantities of particles with a diameter smaller than $1 \mu \mathrm{m}$ were found in the SSF sample at PL8, whereas in samples with sonication treatment at a lower power level (PL3) it was still possible to distinguish large CSF agglomerated particles.

(b) When considering the mechanical properties of mortars, it is concluded that there are increases of 10 to $15 \%$ in the compressive mechanical strength of SSF mortars in comparison with the control mortar, especially the mortars substituted with SSF treated for longer sonication times and higher sonication power levels. In addition, the CSF mortars could never equal the mechanical strength obtained by the SSF mortars, which confirmed the activation of the pozzolan after the sonication process. Furthermore, mechanical strength was slightly improved when the percentage of SSF substituted in the mortar was increased. 


\begin{tabular}{|c|c|c|c|c|c|c|}
\hline \multirow[t]{2}{*}{ Mortars } & \multicolumn{2}{|c|}{ Total weight loss: $\%\left(35-600^{\circ} \mathrm{C}\right)$} & \multicolumn{2}{|c|}{ Weight loss for hydrates: \% } & \multicolumn{2}{|c|}{ Fixed portlandite: \% } \\
\hline & 7 days & 28 days & 7 days & 28 days & 7 days & 28 days \\
\hline PL3 - SSF & 9.09 & $9 \cdot 19$ & $8 \cdot 49$ & $8 \cdot 48$ & $34 \cdot 53$ & 39.83 \\
\hline PL4 - SSF & $8 \cdot 57$ & 8.85 & 8.09 & 8.44 & $47 \cdot 50$ & $65 \cdot 51$ \\
\hline PL6 - SSF & $8 \cdot 23$ & $8 \cdot 61$ & $7 \cdot 82$ & $8 \cdot 27$ & $54 \cdot 59$ & $71 \cdot 53$ \\
\hline PL8 -SSF & $8 \cdot 42$ & $10 \cdot 70$ & 8.09 & $10 \cdot 43$ & $64 \cdot 85$ & 77.93 \\
\hline
\end{tabular}

Table 9. TGA data for 7 and 28 days curing mortars substituted with $10 \%$ SF: effect of sonication power level

(c) The highest fixations of hydrated lime in the SSF mortars were obtained for the longest sonication times. In addition, the values of portlandite fixation were increased when the highest sonication power levels were applied.

\section{Acknowledgements}

The authors are grateful to the Spanish company Ferroatlántica S.L. for their financial support; to the Spanish Agency of International Cooperation and Development (AECID) for the doctorate grant to D.M.-V.; to the Spanish government for their support to the project BIA 2007-63252; and to FEDER for its financial support to our research projects.

\section{REFERENCES}

Appa Rao G (2003) Investigations on the performance of silica fume-incorporated cement pastes and mortars. Cement and Concrete Research 33(11): 1765-1770.

Baweja D, Cao T and Bucea L (2003) Investigation of dispersion levels of silica fume in pastes, mortars and concrete. Proceedings of CANMET/ACI Conference on Concrete Durability, Athens. American Concrete Institute, Farmington Hills, MI, USA, ACI SP 212, pp. 1019-1039.

Bushlaibi AH (2004) Effects of environment and curing methods on the compressive strength of silica fume high-strength concrete. Advances in Cement Research 16(1): 17-22.

Hooton RD (1993) Influence of silica fume replacement of cement on physical properties and resistance to sulphate attack, freezing and thawing, and alkali-silica reactivity. ACI Materials Journal 90(2): 143-151.

Malhotra VM and Metha PK (1996) Pozzolanic and Cementitious Materials, Advances in Concrete Technology, vol. 1. Gordon and Breach Publishers, Amsterdam, The Netherlands.

Martinez-Velandia D (2006) Caracterización y Reactividad de Materiales Puzolánicos: El Humo de Sílice y su Estado de Densificación. PhD thesis, Universidad Politécnica de Valencia, Valencia, Spain.

Martinez-Velandia D, Payá J, Monzó J and Borrachero MV (2008) Granulometric activation of densified silica fume (CSF) by sonication. Advances in Cement Research 20(3): $129-135$

Mehmet G and Erhan G (2007) Strength development and chloride penetration in rubberized concretes with and without silica fume. Materials and Structures 40(9): 953-964.

Payá J, Monzó J, Borrachero MV and Velazquez S (2004) Chemical activation of pozzolanic reaction of fluid catalytic cracking catalyst residue (FCR3) in lime pastes: thermal analysis. Advances in Cement Research 16(3): 123-130.

Roberts LR (1989) Microsilica in concrete. In Materials Science of Concrete, vol. I (Skalny JP and Mindess S (eds)). The American Ceramic Society, Westerville, USA, pp. 197-222.

Sanchez de Rojas MI, Rivera J and Frías M (1999) Influence of the microsilica state on pozzolanic reaction rate. Cement and Concrete Research 29(6): 945-949.

Shayan A, Quick GW and Lancucki CJ (1993) Morphological, mineralogical and chemical features of steam-cured concretes containing densified silica fume and various alkali levels. Advances in Cement Research 5(20): 151-162.

Sidney D and Sadananda S (2006) Densified silica fume: particle sizes and dispersion in concrete. Materials and Structures 39(293): 849-859.

Sidney D, Sadananda S and Niels T (2004) Reaction products of densified silica fume agglomerates in concrete. Cement and Concrete Research 34(9): 1625-1632.

\section{WHAT DO YOU THINK?}

To discuss this paper, please submit up to 500 words to the editor at www.editorialmanager.com/acr by 1 June 2011. Your contribution will be forwarded to the author(s) for a reply and, if considered appropriate by the editorial panel, will be published as a discussion in a future issue of the journal. 